\title{
Solenoid-free current drive via ECRH in EXL-50 spherical torus plasmas
}

\section{Yuejiang Shi ( $\nabla$ yjshi@ipp.ac.cn )}

Enn Science and Technology Development Co., Ltd, Langfang, China https://orcid.org/0000-00029572-3310

\section{Bing Liu}

ENN Science and Technology Development Co., Ltd.

\section{Shaodong Song}

Enn Science and Technology Development Co., Ltd, Langfang, China

\section{Yunyang Song}

Enn Science and Technology Development Co., Ltd, Langfang, China

\section{Xianming Song}

Enn Science and Technology Development Co., Ltd, Langfang, China

\section{Bowei Tong}

Enn Science and Technology Development Co., Ltd, Langfang, China

\section{Shikui Cheng}

Enn Science and Technology Development Co., Ltd, Langfang, China

\section{Wenjun Liu}

Enn Science and Technology Development Co., Ltd, Langfang, China

\section{Mingyuan Wang}

ENN Science and Technology Development Co., Ltd.

\section{Tiantian Sun}

Enn Science and Technology Development Co., Ltd, Langfang, China

\section{Dong Guo}

Enn Science and Technology Development Co., Ltd, Langfang, China

\section{Songjian Li}

Enn Science and Technology Development Co., Ltd, Langfang, China

\section{Yingying Li}

Enn Science and Technology Development Co., Ltd, Langfang, China

\section{Bin Chen}

Enn Science and Technology Development Co., Ltd, Langfang, China

\section{Xiang Gu}

Enn Science and Technology Development Co., Ltd, Langfang, China Jianqing Cai

Enn Science and Technology Development Co., Ltd, Langfang, China 


\section{Di Luo}

Enn Science and Technology Development Co., Ltd, Langfang, China

\section{Debabrata Banerjee}

Enn Science and Technology Development Co., Ltd, Langfang, China

\section{Xin Zhao}

Enn Science and Technology Development Co., Ltd, Langfang, China

\section{Yuanming Yang}

Enn Science and Technology Development Co., Ltd, Langfang, China

\section{Wenwu Luo}

Enn Science and Technology Development Co., Ltd, Langfang, China

\section{Peihai Zhou}

Enn Science and Technology Development Co., Ltd, Langfang, China

\section{Yu Wang}

Enn Science and Technology Development Co., Ltd, Langfang, China

\section{Akio Ishida}

Enn Science and Technology Development Co., Ltd, Langfang, China

\section{Takashi Maekawa}

Enn Science and Technology Development Co., Ltd, Langfang, China

\section{Minsheng Liu}

Enn Science and Technology Development Co., Ltd, Langfang, China

\section{Baoshan Yuan}

Enn Science and Technology Development Co., Ltd, Langfang, China

\section{Yueng-Kay Peng}

ENN Science and Technology Development Co., Ltd. https://orcid.org/0000-0003-2948-1058

\section{Article}

Keywords: spherical tokamak (ST), EXL-50, plama

Posted Date: May 10th, 2021

DOl: https://doi.org/10.21203/rs.3.rs-492727/v1

License: (c) (1) This work is licensed under a Creative Commons Attribution 4.0 International License. Read Full License 


\title{
Solenoid-free current drive via ECRH in EXL-50 spherical torus plasmas
}

Yuejiang Shi*, Bing Liu*, Shaodong Song, Yunyang Song, Xianming Song, Bowei Tong, Shikui Cheng, Wenjun Liu, Minyuan Wang, Tiantian Sun, Dong Guo, Songjian Li, Yingying Li, Bin Chen, Xiang Gu, Jianqing Cai, Di Luo, Debabrata Banerjee, Xin Zhao, Yuanming Yang, Wenwu Luo, Peihai Zhou, Yu Wang, A.Ishida, T. Maekawa, Minsheng Liu, Baoshan Yuan, Y-K Martin Peng* and the EXL-50 team

Enn Science and Technology Development Co., Ltd, Langfang, China Hebei Key Laboratory of Compact Fusion, Langfang 065001, China

*E-mail of corresponding author: shiyuejiang@enn.cn $\quad \underline{\text { liubingw@enn.cn }}$ pengyuankai@enn.cn

\begin{abstract}
.
As a new spherical tokamak (ST) designed to simplify engineering requirements of a possible future fusion power source, the EXL-50 experiment features a low aspect ratio (A) vacuum vessel (VV), encircling a central post assembly containing the toroidal field coil conductors. Multiple electron cyclotron resonance heating (ECRH) resonances are located within the VV to possibly improve current drive effectiveness. The energetic electrons are observed via hard X-ray detectors, carry the bulk of the plasma current ranging from 50kA to $150 \mathrm{kA}$, which is maintained for more than $1 \mathrm{~s}$ duration. It is observed that over one Ampere current can be maintained per Watt of ECRH power issued from the $28-\mathrm{GHz}$ gyrotrons. The plasma current with high line-density (approaching $10^{19} \mathrm{~m}^{-}$ ${ }^{2}$ ) has been achieved for plasma currents as high as 76kA. An analysis was carried out combining reconstructed multi-fluid equilibrium, guiding-center orbits, and resonant heating mechanisms. It is verified that in EXL-50 a broadly distributed current of energetic electrons creates smaller closed magnetic-flux surfaces of low aspect ratio that in turn confine the thermal plasma electrons and ions and participate in maintaining the equilibrium forcebalance.
\end{abstract}

Great progress has been achieved in magnetic confinement fusion research based on the Tokamak since 50 years ago when the first stable high temperature plasma was observed in the T-3 tokamak [1,2]. The tokamak has been the most investigated and furthest advanced configuration among the magnetic confinement fusion systems. More recently, the spherical torus (ST) concept of aspect ratios around 1.5 [3, 4] has been experimentally (START [5], NSTX [6], MAST [7], and Globus-M [8]) tested to realize a substantially higher plasma beta compared to the tokamak of aspect ratios around 3, and is an attractive candidate for realizing a relatively compact fusion reactor.

The tokamak plasma current is required to insure a high plasma confinement capability to restrain transport losses from the core to the edge. The start-up and ramp-up of this current has been commonly driven by a toroidal electric field induced by current changes in a centre 
solenoid (CS) magnet. This however causes engineering difficulties for the ST due to the limited space available within a narrow centre column. Further, a CS magnet is capable of sustaining the plasma current over limited time periods, which is to be augmented by noninductive methods in a future fusion reactor. To develop a solenoid-free current drive capability therefore has been an important research endeavour for the STs. On the positive side, removing the CS allows additional space to increase the toroidal field (TF), further improving compactness and economy.

The original physics concept and principle of the ENN Spherical Torus with a major radius 50 cm (EXL-50) in Energy iNNovation (ENN) Science and Technology Development Co. was recently proposed by Peng [9]. One of the key EXL-50 experimental goals is to test the efficacy of electron cyclotron resonance heating (ECRH) and current drive in the absence of an CS magnet. CS-free ECRH and current drive has been tested in several earlier ST devices (CDXU [10], LATE [11-15], TST-2 [16-17], MAST [18-19], and QUEST [20-26]). A toroidal current of $1.05 \mathrm{kA}$ was generated using about $8 \mathrm{~kW}$ of ECRH power on CDX-U [9], proving the possibility of current start-up by ECRH alone. Later, a 7kA plasma current was generated by about 30kW ECRH in LATE [11-12]. A current flattop with closed flux surface (CFS) plasma was sustained for $60 \mathrm{~ms}$ in LATE, proving the potential for steady-state ECRH and current drive of the ST plasmas. In MAST, a plasma current of 73kA was produced by $60 \mathrm{~kW}$ ECRH power with the help of the unique grooved mirror-polarizer installed on the central rod [18]. In QUEST, a plasma current of 90kA was obtained with about 200kW ECRH power through combined first and second harmonic resonances [24].

In this paper, we present the latest ECRH experimental results from EXL-50. Not only are the operational parameters of CS-free current drive by ECRH significantly expanded, but also observed are some remarkable plasma behaviour. Discharges with plasma currents substantially above 100kA are routinely obtained in EXL-50, with the current flat-top sustained for up to or beyond 2 seconds. More than 1A current per Watt of ECRH power issued from the gyrotrons, averaged over hundreds of discharges, have been accumulated. At line-densities approaching $10^{19} \mathrm{~m}^{-2}$, plasma currents as high as 76kA have been achieved.

The EXL-50 device is a medium-sized ST with a cylindrical vacuum vessel (see, Fig. 1). Six poloidal field (PF) coils are located outside the vacuum vessel and the TF coil conductors. Inner limiters on the center column and outer limiters on the vessel wall have leading edges at $0.186 \mathrm{~m}$ and $1.512 \mathrm{~m}$ in major radius, respectively. Two microwave frequencies have been utilized so far, 28-GHz from high power gyrotrons for higher toroidal field discharges and 2.45-GHz from 
low power magnetrons for lower toroidal field discharges and wall cleaning. Fig. 1 shows the poloidal cross section of the EXL-50 device. Two sets of $28 \mathrm{GHz}$ gyrotrons $(50 \mathrm{~kW}$ source power for ECRH1 and 400kW for ECRH2) are available to inject power through an outboard ports above the mid-plane. Another $400 \mathrm{~kW} 28 \mathrm{GHz}$ gyrotron (ECRH3) and two sets of $2.45 \mathrm{GHz}$ magnetrons (30kW source power each) are available to inject power through the mid-plane ports. The toroidal injection angles of the ECRH systems can be adjusted over limited ranges (as shown in Fig.1b). Both the $2.45-\mathrm{GHz}$ and the $28-\mathrm{GHz}$ systems are arranged to inject primarily ordinary-mode (O-mode) wave in recent experiments on the EXL-50. When the electric current of a 12-turn TF coils per turn was set to about 100kA, the fundamental and higher ECR layers (up to five resonances) coexist within the EXL-50's vacuum region within the limiters (as shown in Fig.1a). The electron density is measured by single-chord tangential microwave interferometer. Two CdTe detectors with energy resolution are applied to observe the forward and backward bremsstrahlung hard x-ray (HXR) emission.

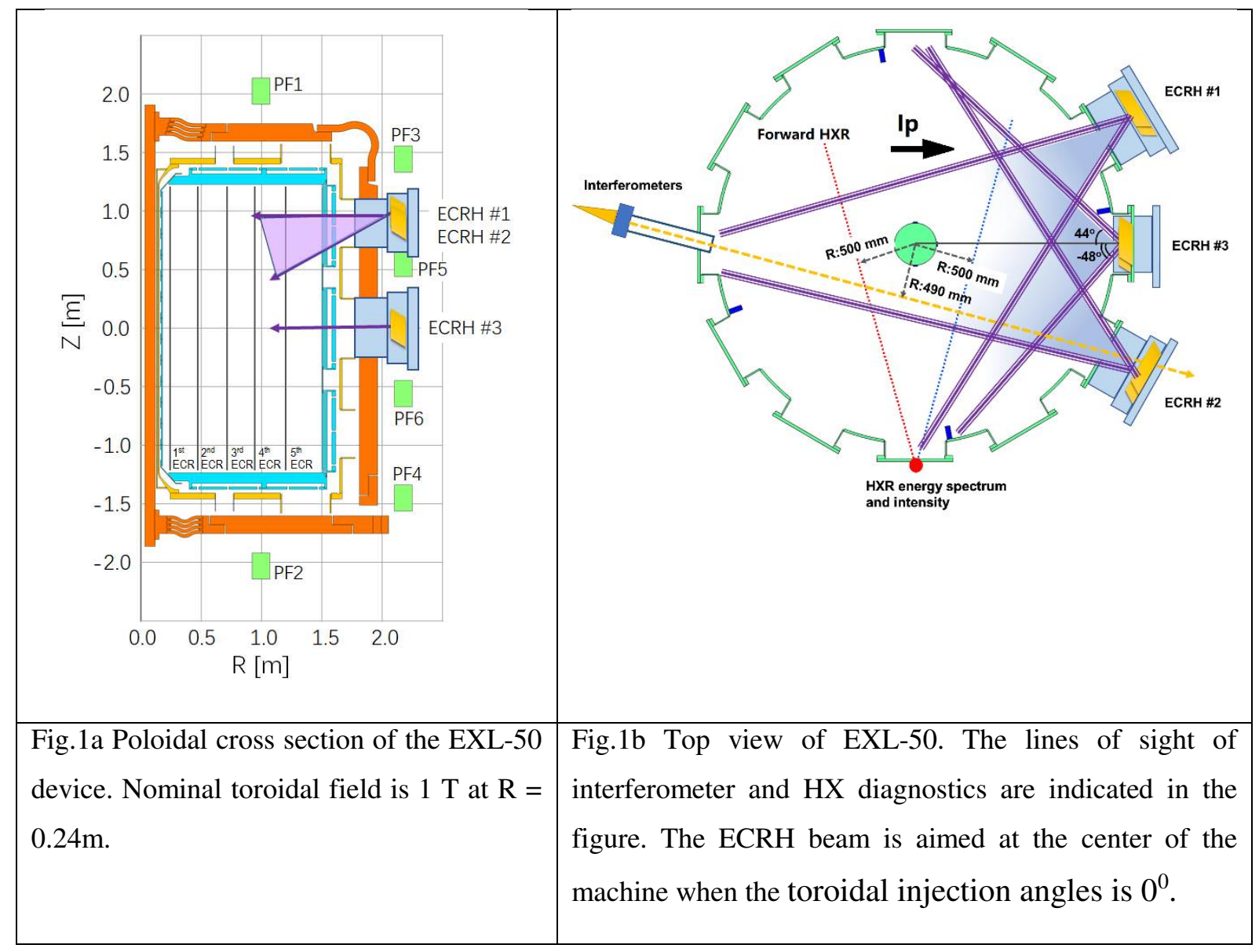

Here, a simplified current drive effectiveness $\eta_{A / W}$ is defined as follows and utilized: 


$$
\eta_{A / W}=\frac{I_{P}}{P_{E C R H}}
$$

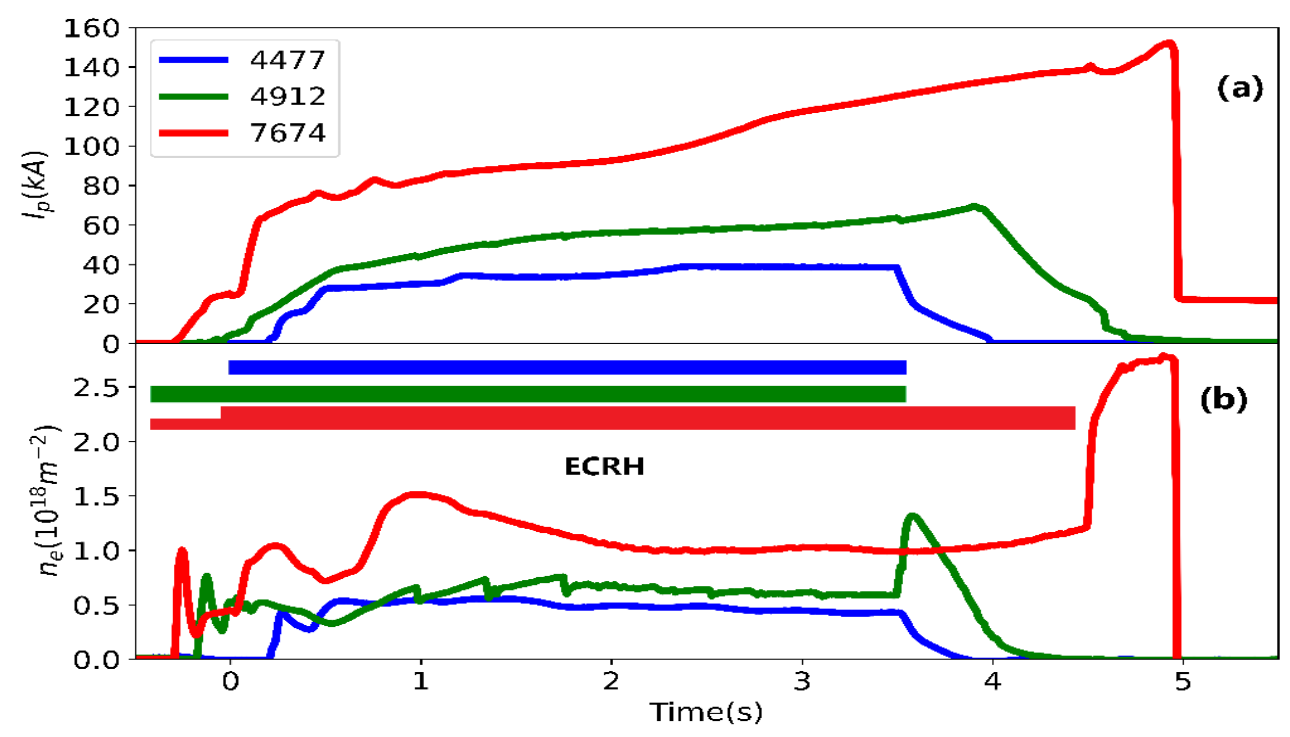

Fig.2 The discharge waveforms for different $28 \mathrm{GHz}$ ECRH heating power. (a) plasma current; (b) line integrated density. $\mathrm{P}_{\mathrm{ECRH}}$ was $20 \mathrm{~kW}$ in shot 4477 and $45 \mathrm{~kW}$ in shot 4912 . Two gyrotrons are used in shot 7674. One gyrotron injected $20 \mathrm{~kW}$ from $-0.3 \mathrm{~s}$ to $0 \mathrm{~s}$ and the other gyrotron injected $115 \mathrm{~kW}$ from $0 \mathrm{~s}$ to $4.5 \mathrm{~s}$.

where $\mathrm{I}_{\mathrm{P}}$ is the plasma current, $\mathrm{P}_{\mathrm{ECRH}}$ is the ECRH power issued from the gyrotrons. Fig.2 shows the typical discharge waveforms with different $28 \mathrm{GHz}$ ECRH heating power in EXL-50. The $\eta_{A / W}$ can reach $2 \mathrm{~A} / \mathrm{W}(40 \mathrm{kA} / 20 \mathrm{~kW})$ for low power ECRH plasma. The $\eta_{A / W}$ is $1.55 \mathrm{~A} / \mathrm{W}$ $(70 \mathrm{kA} / 45 \mathrm{~kW})$ for moderate power ECRH plasma and 1.22A/W $(140 \mathrm{kA} / 115 \mathrm{~kW})$ for further increased power ECRH plasma. The $P_{E C R H}$ in this paper is the power measured at the matching optical unit (MOU) which is close to the exit power of the gyrotrons. The power delivered from the antenna inside the vacuum vessel is unknown at present. The duration of high current ( $I_{P}$ $>100 \mathrm{kA}$ ) for the higher power ECRH plasma in Fig.2 is more than 2s. The total pulse length for $28 \mathrm{GHz}$ ECR heating plasma is less than $6 \mathrm{~s}$ limited by temperature rise at the top joints of the TF coils at 100kA electric current. One notable phenomenon as shown in Fig. 2 is the density jumps as the ECRH power is turned off, indicating possibly a cessation of density pump-out by $\mathrm{ECH}$ [25], which is not addressed in this paper.

Fig. 3 shows the relation of $I_{p}$ V.s. $P_{E C R H}$ for about 180 successful shots in EXL-50. The general trend in Fig. 3 is that the Ip increases with PECRH. On the other hand, it is also can be seen in Fig. 3 that the $I_{p}$ varies in quite large range for the same $P_{E C R H}$. Notably, changes in the currents of PF coils has substantial effects on $\eta_{\mathrm{A} / \mathrm{w}}$. Fig.4 clearly shows that the $\mathrm{I}_{\mathrm{p}}$ increases with the 
current of PF5\&6 coils for the same $\mathrm{P}_{\mathrm{ECRH}}$ and density. More statistical information from 180 shots is shown in Fig.4b. It can be found that for fixed $P_{E C R H}$ the $I_{p}$ increases linearly with the external vertical magnetic field $\mathrm{B}_{\mathrm{v}}$. The force balance between the expansion of the plasma itself and external magnetic compress must be sustained for a stable equilibrium structure. So much potential for raising $\eta_{\mathrm{A} / \mathrm{w}}$ further remains unexplored at present through optimization of PF coil current.

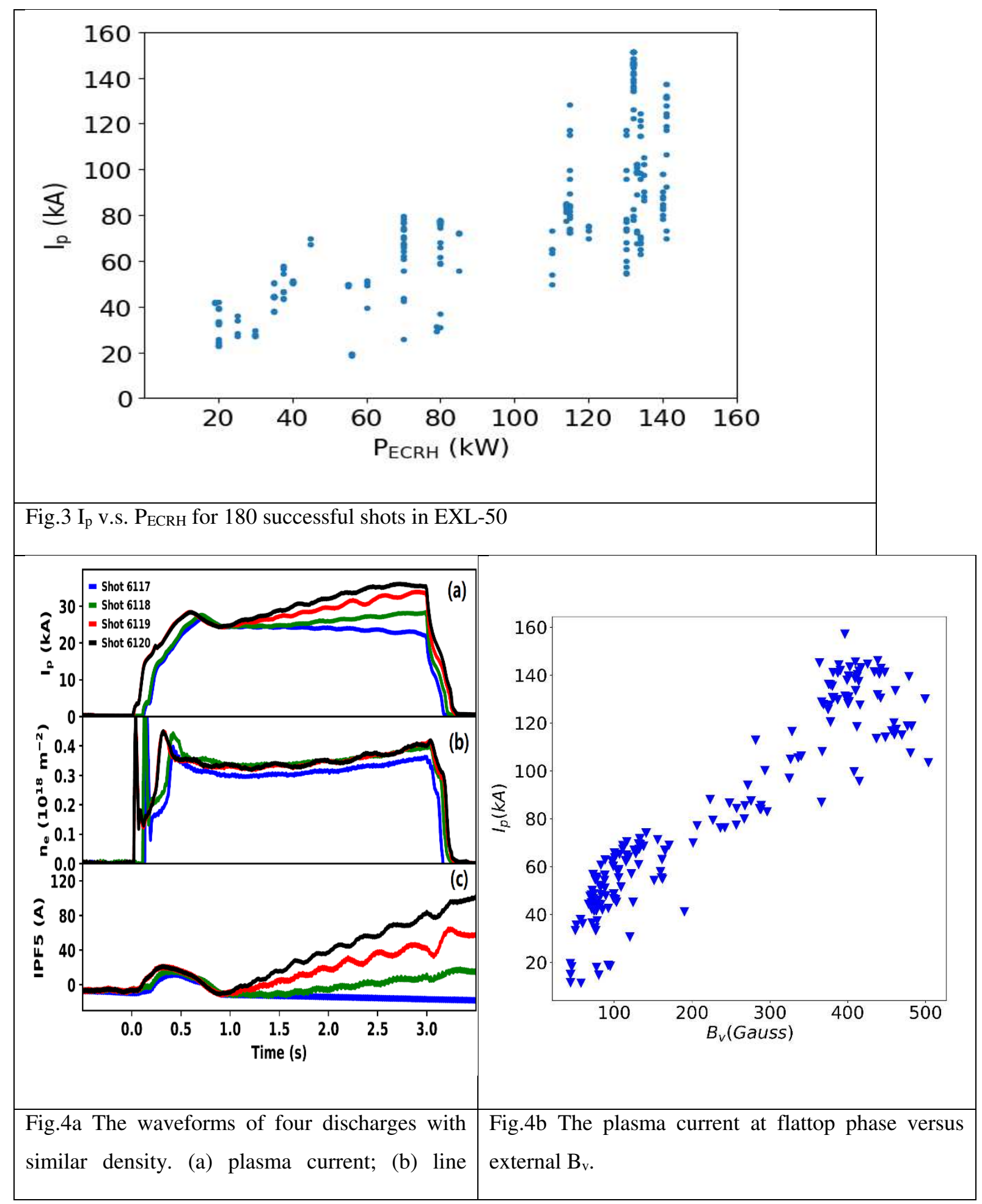




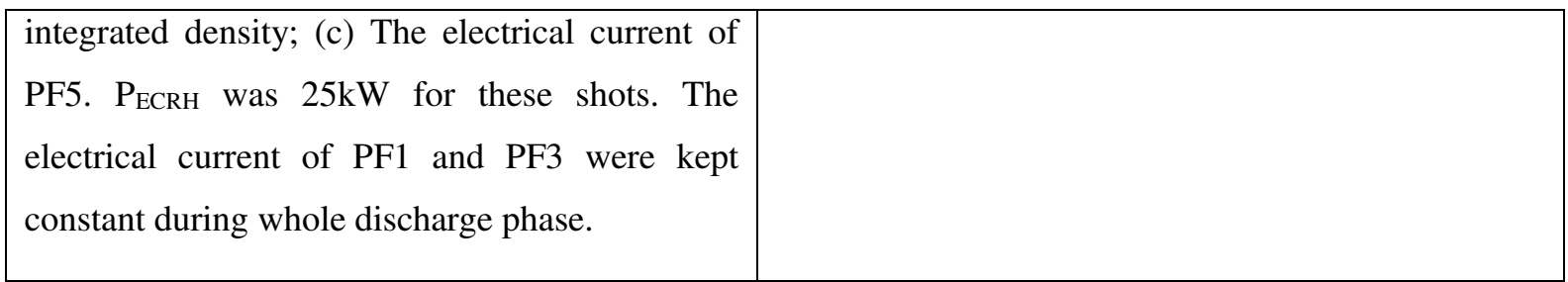

The Pfirsch-Schluter (PS) current is a dominant component during the initial start-up phase, and drastically decreases with increasing $\mathrm{B}_{\mathrm{v}}$ following the formation of CFS. The bootstrap current drive by the pressure gradient is at present estimated to be less than several percent for these EXL-50 plasmas. The conventional Electron cyclotron current drive (ECCD) via Fisch-Boozer mechanism [28] or Ohkawa mechanism [29] can also contribute to the noninductive current. However, such ECCD effects have not been confirmed in EXL-50's experiments. Fig.5 shows the waveforms of two shots in EXL-50. Although the toroidal angle for the ECRH antenna was set at $-16^{0}$ for count-current drive in shot 7448 and $17^{0}$ for co-current drive in shot 7449 , the plasma current remained largely unchanged.

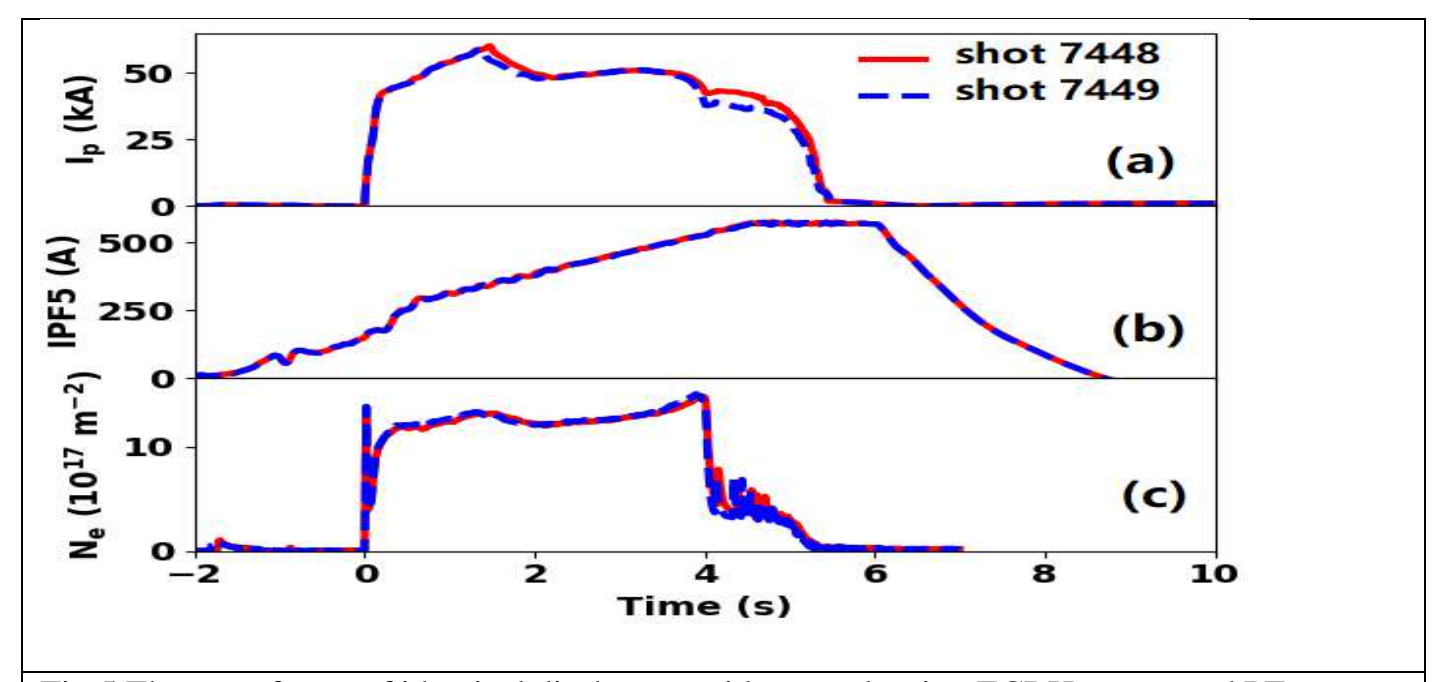

Fig.5 The waveforms of identical discharges with same density, ECRH power and PF current. (a) plasma current; (b) The electrical current of PF5; (b) line integrated density;

QUEST and LATE's experiments have proven that the energetic electrons play a primary role for the CS-free current drive. EXL-50's experimental results confirm that the plasma current is mainly carried by such energetic electrons. The shot shown in Fig.6 is a very stable and well-controlled discharge, showing a nearly stationary plasma current, electron density, as well as a zero loop voltage from $1.5 \mathrm{~s}$ to $4.5 \mathrm{~s}$. During the entire dischargge, the plasma current , and hard x-ray intensity and its photon temperature (the average energy of energetic electrons) vary conjointly in magnitude. It is seen that both the number and the energy of energetic electrons contribute directly to the increase of ECRH plasma current. 


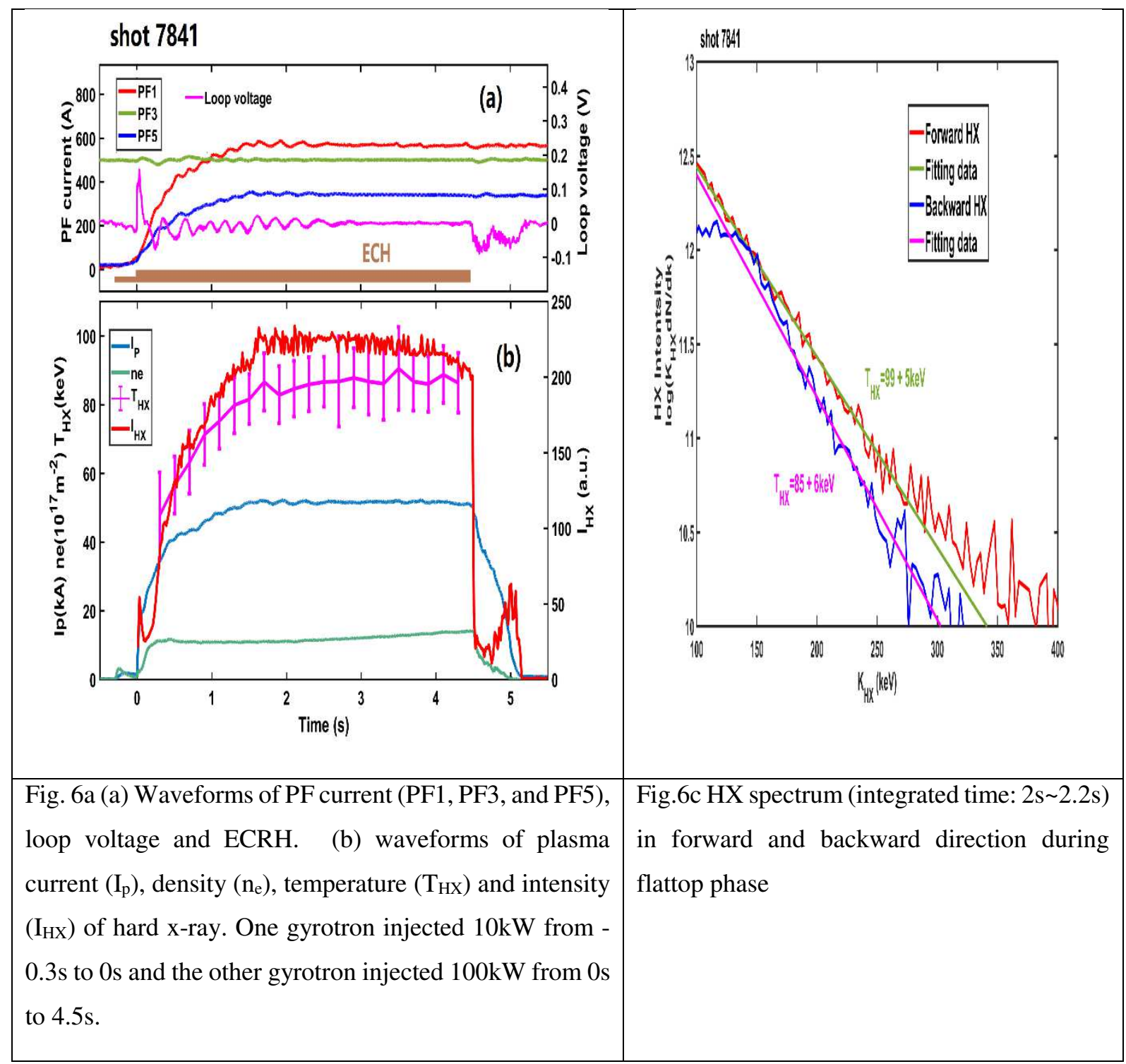

It should be noted that the role of induction in the CS-free ECRH driven current remains unresolved. That is, does the toroidal electric field induced by changes in the PF coil and plasma currents accelerate the already decoupled energetic electrons to even higher energies and and carry a significant plasma current fraction during a discharge? Experiments dedicated to resolving this question were carried out. As indicated in Fig. 6a, the currents of PF3 and PF4 (not indicated) were kept constant during the entire discharge. The currents of PF1\&2 and PF5\&6 were ramped-up slowly until $1.5 \mathrm{~s}$ and kept constant through to $6 \mathrm{~s}$. The loop voltage oscillated near zero between $1.5 \mathrm{~s}$ and $2.5 \mathrm{~s}$ and became zero between $2.5 \mathrm{~s}$ and $4.5 \mathrm{~s}$. The largest value of loop voltage of $+0.17 \mathrm{~V}$ (counter-clockwise when viewed from top) appears at $0.037 \mathrm{~s}$, in the direction opposite to the plasma current (clockwise when viewed from top).. in addition, the velocity distribution of energetic electrons driven by ECRH is different from that of runaway electrons induced by a toroidal electric field. In the former case, the energetic electrons possess similar magnitudes of parallel and perpendicular velocities, while in the latter, the 
parallel velocities dominates. Fig.6c shows the hard x-ray intensity and energy spectrum in forward (count-current) direction and backword (co-current) direction, indicating relatively moderate differences. Further, the energetic electrons can be strongly accelerated in the parallel direction by the relative high loop voltage during current ramp-down after the ECRH is turned off. These experimental observations indicate that the inductive and runaway-like current drive mechanisms are not significant in the CS-free ECRH plasmas.

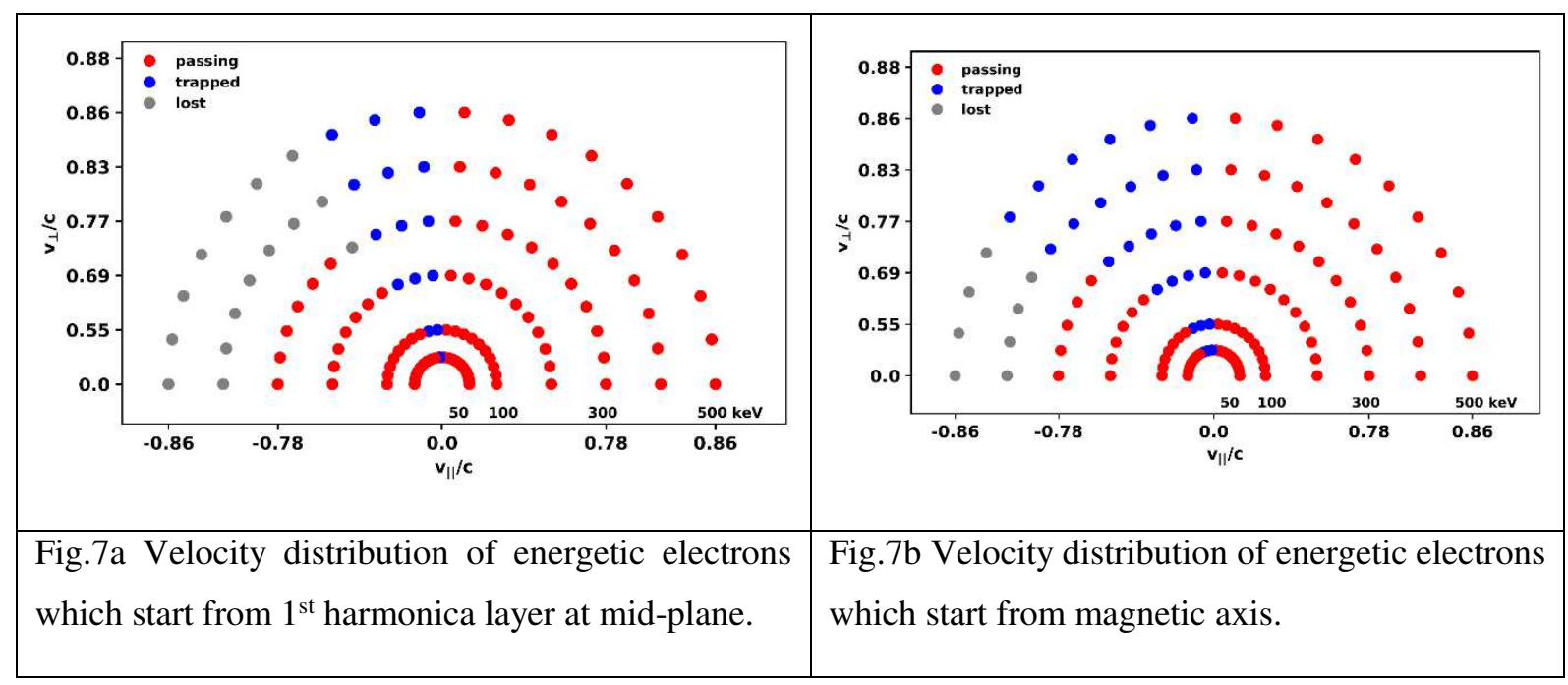

A key question regarding the very high current drive effectiveness $\left(\eta_{A / W}=1.2 \mathrm{~A} / \mathrm{W} \sim 2\right.$ A/W) in EXL-50 via the energetic electrons may be addressed by analysing the asymmetric region of orbit containment of the energetic electrons. Fig.7 shows the orbit analysis for energetic electrons in velocity-energy space. A three-fluid equilibrium reproducing a 50kA EXL-50's plasma was obtained via the multi-fluid equilibrium model [30] for the computation for the guiding-center orbits [31]. A strongly asymmetric distribution in toroidal direction, in the $\mathrm{v}_{\|}, \mathrm{v}_{\perp}$, and energy space, is obtained, accentuated as the electron energy increases toward the limiting energy of orbit containment. Further, the design of EXL-50 (as shown in Fig.1a) permits the coexistence of five ECR layers within the vacuum vessel. Considering the effect of relativistic Doppler shift [23], the resonance layers for energetic electrons broaden in major radius. Fig.8a shows the radial dependence of the characteristic resonant energies for the fundamental and harmonic ECW for EXL-50. For energy of electrons above 100keV, the width of a resonance upshifts to overlap with the downshifted resonance of the next higher harmonic. It can be seen that the individual resonance widths for the energetic electrons fill the entire space inside EXL-50's vacuum vessel.

The single-pass absorption of ECW is estimated to be relatively low in EXL-50 for the present range of plasma densities. The smooth stainless steel vacuum vessel walls and limiters, 
including those on the center column, assist in ensuring multiple reflected paths of the injected ECW back to the plasma. Wall-reflection further helps by converting O-mode wave to the Xmode and vice versa, thus taking advantage of the higher efficiency of X-modes by energetic electrons [26]. Another notable feature of EXL-50's plasma is that the cross section of the plasma current carried by the energetic electrons is much bigger than that of CFS during the flattop phase of plasma current. Fig.8b shows the current profile and last close flux surface (LCFS) for a 120kA discharge shown in Fig.2, computed via the multi-fluid equilibrium model [30]. A significant fraction of the plasma current (52\% in this case) is flowing outside the LCFS.

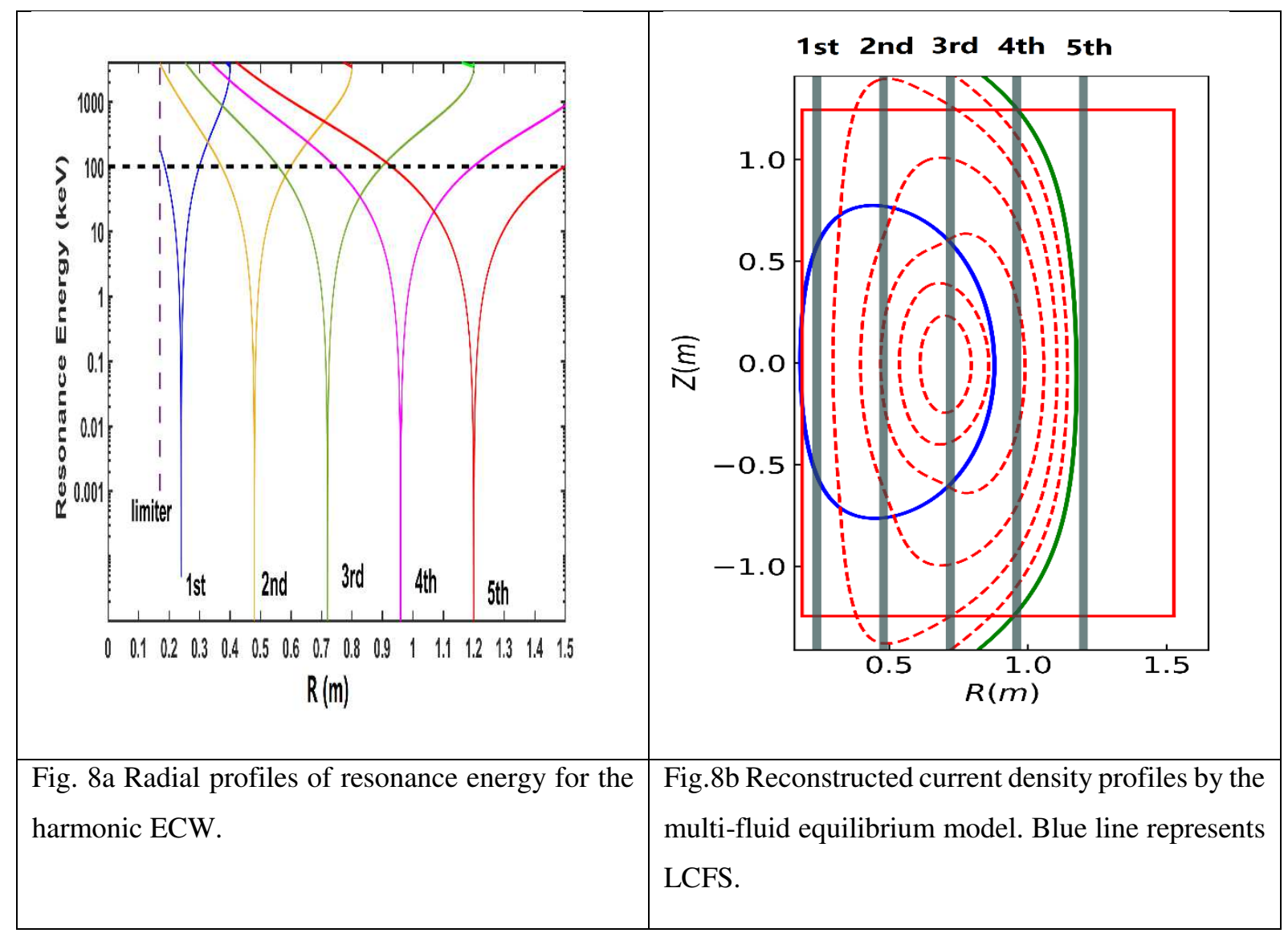

High density ECRH discharges are also obtained in EXL-50. The line averaged density can be as higher as three times of the ordinary mode (O-mode) cut-off density in the $2.45 \mathrm{GHz}$ ECH discharges. In the $28 \mathrm{GHz}$ ECH discharges, the line average density near the O-mode cutoff $\left(\sim 9 \times 10^{18} \mathrm{~m}^{-3}\right)$ has been measured. The core density for shot 7814 in Fig.9 would exceed the cut-off density if the density profile within the LCFS has a parabolic shape. It is surmised that the electron Bernstein wave (EBW) has been excited and played key role to heat plasma and drive current for such high density discharges. In shot 7814, density ramp-up caused a decrease in plasma current. In fact, the continuous current decrease during the density flattop is mainly caused by the yet-to-be optimized PF current setting. After eliminating the influence of PF 
current, the plasma current only decrease one third (from 116kA to 76kA) when the line density increases 6 times (from $0.11 \times 10^{19}$ to $0.77 \times 10^{19} \mathrm{~m}^{-2}$ ). The hard $\mathrm{x}$-ray signal in Fig.9 indicates that the energetic electron can be still efficiently produced and maintain a dominant component of the plasma current in high density ECH discharges.

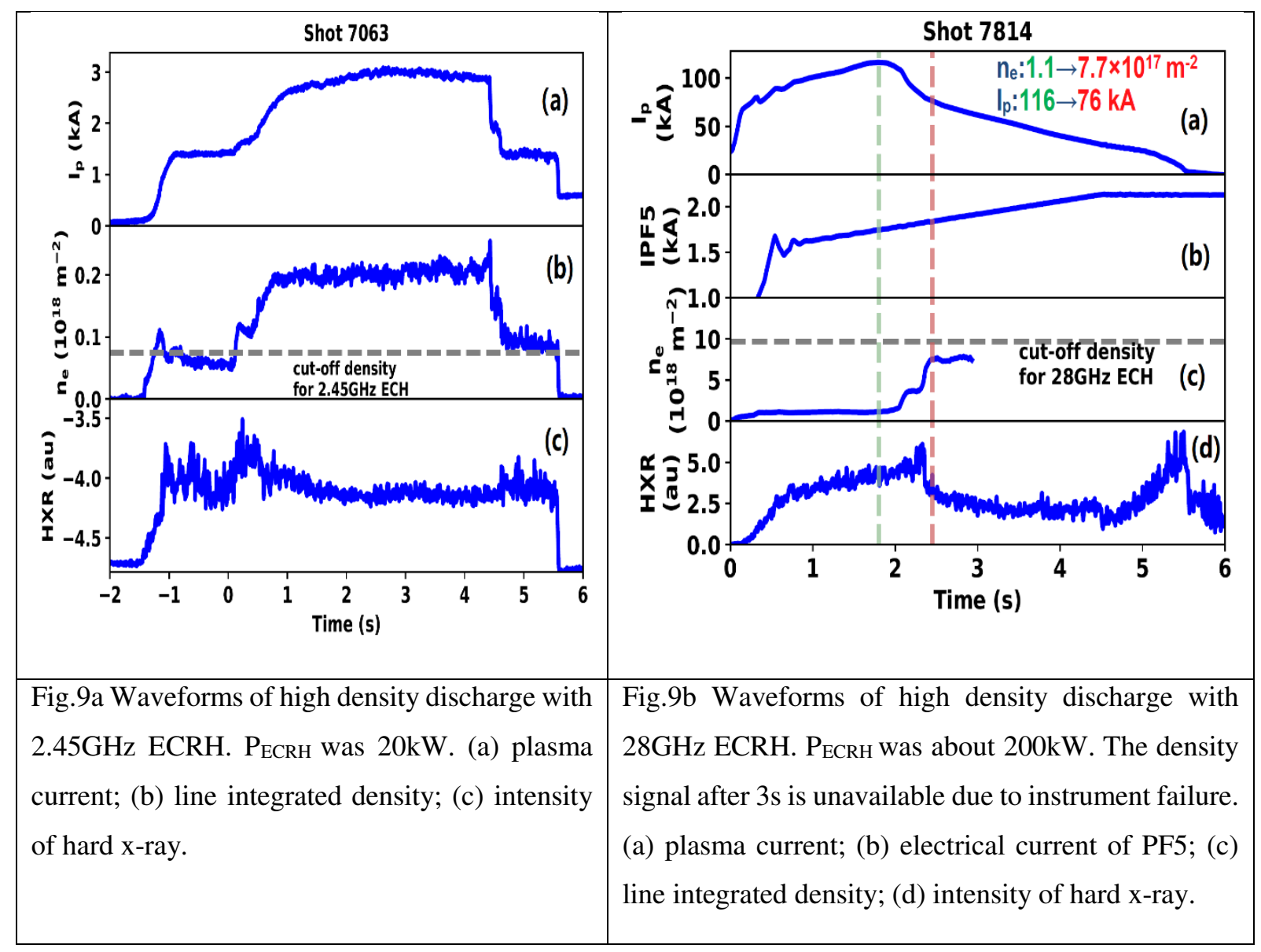

New records of driven plasma current and current drive effectiveness have been obtained during the CS-free ECRH-only operation on EXL-50. The energetic electrons play a unique and important role in EXL-50's plasmas. Metal wall of the vacuum vessel effecting multireflective absorption of high multi-harmonic resonances resulted in highly effective acceleration of the energetic electrons. The asymmetric distribution of the energetic electrons in velocity-energy space based on orbit analysis in a multi-fluid equilibrium is another key feature of the very high current driven effectiveness observed. However, the physics mechanism for the solenoid-free ECRH current drive is not yet well understood and quantifiable. Nevertheless, these results demonstrate an exceptional potential of ECRH to achieve and maintain highly efficient steady-state current drive under low and high densities in the CS-free EXL-50 device. Theory, modelling and simulation to better describe the full range 
of mechanisms associated with the CS-free current drive observed will be systematically developed in the future. Steady-state high current and density experiments using high ECRH power on EXL-50 will continue to make additional physics contributions towards an eventual realization of a commercial fusion reactor.

\section{Reference}

[1] Artsimovich, L. A., Brobrovskii, G. A., Gorbunov, E. P., Ivanov, D. P., Kirillov, V. D., Kuznetsov, E. I., Mirnov, S. V., Petrov, M. P., Rasumova, K. A., Strelkov, V. S., and Shcheglov, D. A., Proc. Third Intern. Conf. on Plasma Physics and Nuclear Fusion, Novosibirsk, 1968, 1, 157 (Paper CN24/B1) (International Atomic Energy Agency, Vienna, 1969)

Artsimovich, L. A. et al., Thermal insulation of plasma in the Tokamaks, 1967 Sov. At. Energy (Soviet Atomic Energy) 22 325-331

[2] N. J. Peacock, D. C. Robinson, M. J. Forrest, P. D. Wilcock \& V. V. Sannikov, Measurement of the Electron Temperature by Thomson Scattering in Tokamak T3, Nature 224, 488 - 490 (01 November 1969); doi:10.1038/224488a0

[3] Peng Y.-K.M. and Strickler D.J., Features of spherical torus plasmas, Nucl. Fusion 26 769-777 (1986)

[4] Peng Y.-K.M., The physics of spherical torus plasmas, Phys. Plasmas 7, 1681-1692 (2000).

[5] Sykes A., Akers R., Appel L., Carolan P.G., Conway N.J., et al, High- $\beta$ performance of the START spherical tokamak, Plasma Phys. Control. Fusion 39, B247-260(1997)

[6] Synakowski E.J., Bell M. G., Bell R.E., Bigelow T., Bitter M., et al., The national spherical torus experiment (NSTX) research programme and progress towards high beta, long pulse operating scenarios, Nucl. Fusion 43 1653-1664 (2003)

[7] Buttery R. J., Akers R., Arends E., Conway N. J., Counsell G. F., et al., Stability at high performance in the MAST spherical tokamak, Nucl. Fusion 44 1027-1035 (2004)

[8] V.K. Gusev, S.E. Aleksandrov, V. Kh Alimov, I.I. Arkhipov, B.B. Ayushin, et al., Overview of results obtained at th Globus-M spherical tokamak, Nucl. Fusion 49104021 (2009)

[9] Y.-K. M. Peng et al, Plasma conditions under which the p-11B fusion Lawson criterion could be eased, https://assets.researchsquare.com/files/rs-93644/v1/ea84d194-4141-4f9b-90c3-e262fdccb237.pdf;

P.R.China Patent pending (application no. 202010292584.X).

[10] C. B. Forest, Y. S. Hwang, M. Ono, and D. S. Darrow, Internally Generated Currents in a SmallAspect-Ratio Tokamak Geometry, Phys. Rev. Lett. 68, 3559-3562 (1992)

[11] T. Maekawa, Y. Terumichi, H. Tanaka, M. Uchida, T. Yoshinaga, Formation of spherical tokamak equilibria by ECH in the LATE device, Nucl. Fusion 45 1439-1445 (2005)

[12] T. Yoshinaga, M. Uchida, H. Tanaka, and T. Maekawa, Spontaneous Formation of Closed-Field Torus Equilibrium via Current Jump Observed in an Electron-Cyclotron-Heated Plasma, Phys. Rev. Lett. 96, 125005 (2006)

[13] M. Uchida, T. Yoshinaga, H. Tanaka, T. Maekawa, Rapid Current Ramp-Up by Cyclotron-Driving Electrons beyond Runaway Velocity, Phys. Rev. Lett. 104, 065001 (2010)

[14] K. Kuroda, M. Wada, M. Uchida, H. Tanaka, T. Maekawa, Shift in principal equilibrium current from a vertical to a toroidal one towards the initiation of a closed flux surface in ECR plasmas in the LATE device, Plasma Phys. Control. Fusion 58, 025013 (2016)

[15] H. Tanaka, Y. Nozawa, M. Uchida, R. Kajita, Y. Omura, et al., Electron Bernstein wave heating and current drive with multi-electron cyclotron resonances during non-inductive start-up on LATE, in Proceedings of 27th IAEA Fusion Energy Conference, Ahmedabad, India (2018), p. EX/P3-19 


\section{1-EXL-50ECRH}

[16] A. Ejiri, Y. Takase, T. Oosako, T. Yamaguchi, Y. Adachi, et al., Non-inductive plasma current start-up by EC and RF power in the TST-2 spherical tokamak, Nucl. Fusion 49065010 (2009)

[17] Y.Takase, A. Ejiri, H. Kakuda, T. Oosako, T. Shinya,, Non-inductive plasma initiation and plasma current ramp-up on the TST-2 spherical tokamak, Nucl. Fusion 53063006 (2013)

[18] V.F. Shevchenko, M.R. O'Brien, D. Taylor, A.N. Saveliev, Electron Bernstein wave assisted plasma current start-up in MAST, Nucl. Fusion 50022004 (2010)

[19] V. F. Shevchenko, T. Bigelow, J. B. Caughman, S. Diem, J. Mailloux, et al., Long Pulse EBW start-up experiments in MAST, EPJ Web Conf. 87, 02007 (2015)

[20] K. Hanada, H. Zushi, H. Idei, K. Nakamura, M. Ishiguro, et al., Non-Inductive Start up of QUEST Plasma by RF Power, Plasma Science and Technology, 13, 307-311 (2011)

[21] M. Ishiguro, K. Hanada, H. Liu, H. Zushi, K. Nakamura, et al., Non-inductive current start-up assisted by energetic electrons in Q-shu University experiment with steady-state spherical tokamak, Phys. Plasmas 19, 062508 (2012)

[22] S. Tashima, H. Zushi, M. Isobe, K. Hanada, H. Idei, et al., Role of energetic electrons during current ramp-up and production of high poloidal beta plasma in non-inductive current drive on QUEST, Nucl. Fusion 54, 023010 (2014)

[23] H. Idei, T. Kariya, T. Imai, K. Mishra, T. Onchi, et al., Fully non-inductive second harmonic electron cyclotron plasma ramp-up in the QUEST spherical tokamak, Nucl. Fusion 57,126045 (2017).

[24] H. Idei, T. Onchi, T. Kariya, et al., fully non-inductive 2 nd harmonic electron cyclotron current rampup with polarized focusing-beam in the quest spherical tokamak, in Proceedings of 27th IAEA Fusion Energy Conference, Ahmedabad, India (2018), EX/P3-21

[25] H. Idei, T. Onchi, K. Mishra, H. Zushi, T. Kariya, et al., Electron heating of over-dense plasma with dual-frequency electron cyclotron waves in fully non-inductive plasma ramp-up on the QUEST spherical tokamak, Nucl. Fusion 60, 016030 (2020)

[26] T. Onchi, H. Idei, M. Fukuyama, D. Ogata, R. Ashida, et al., Non-inductive plasma current ramp-up through oblique injection of harmonic electron cyclotron waves on the QUEST spherical tokamak, Phys. Plasmas 28, 022505 (2021)

[27] C. Angioni, E. Fable, M. Greenwald, M. Maslov, A. G. Peeters, H. Takenaga and H. Weisen, Particle transport in tokamak plasmas, theory and experiment, Plasma Phys. Control. Fusion 51, 124017 (2009)

[28] N.J.Fisch, and A.H. Boozer, Creating an Asymmetric Plasma Resistivity with Waves, Phys. Rev. Lett. 45, 720-722 (1980)

[29] T. Ohkawa, Steady-state operation of tokamaks by $r$-f heating, General Atomics Report No. GAA13847 (1976).

[30] A. Ishida, Y.K. M. Peng, W. J. Liu, Four-Fluid Axisymmetric Plasma Equilibrium Model Including Relativistic Electrons and Computational Method and Results, Phys. Plasmas 28, 032503 (2021)

[31] T. Maekawa, T. Yoshinaga, M. Uchida, F. Watanab and H. Tanaka, Open field equilibrium current and cross-field passing electrons as an initiator of a closed flux surface in EC-heated toroidal plasmas,

Nucl. Fusion 52, 083008 (2012) 


\section{Figures}
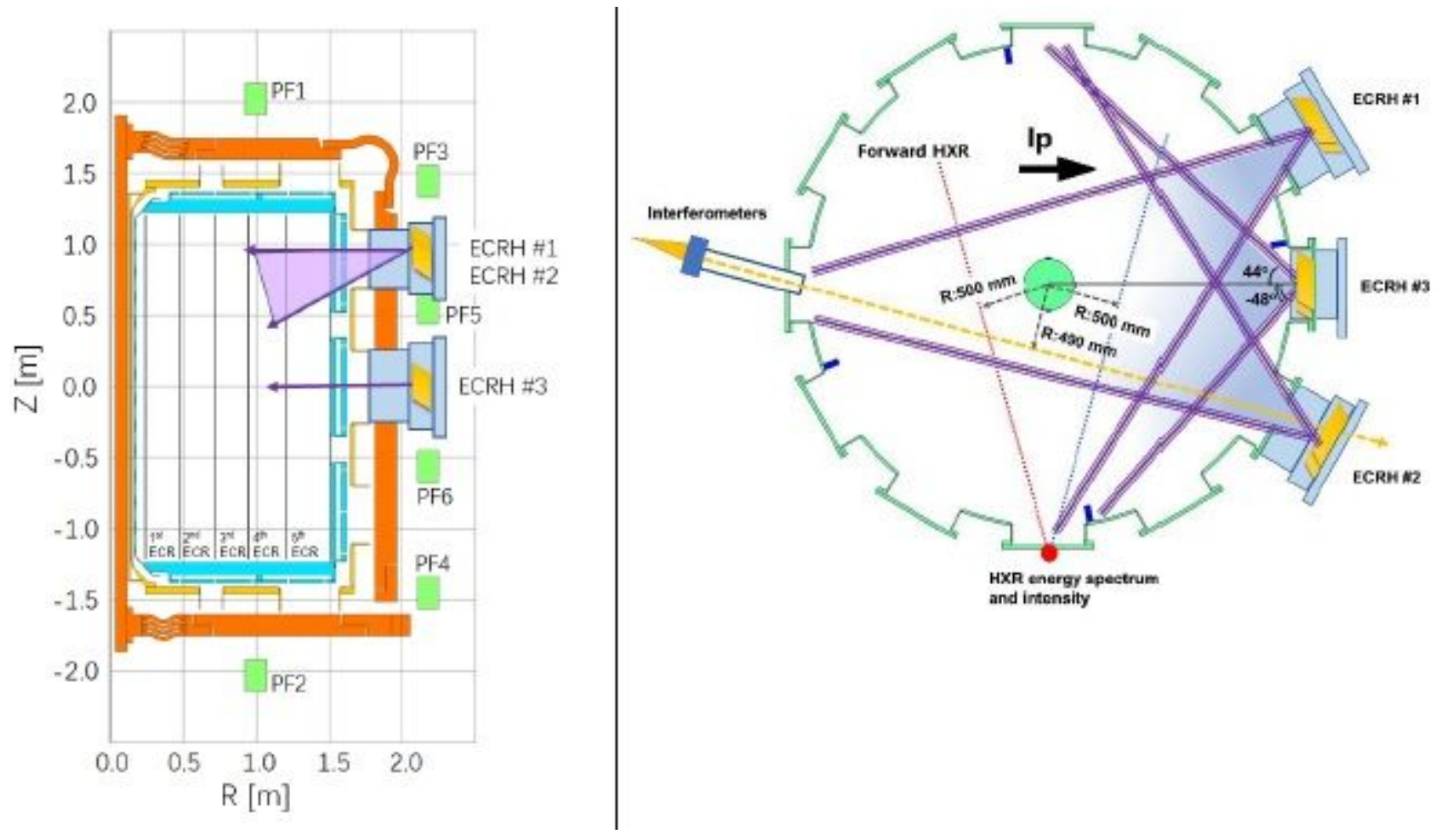

Figure 1

a Poloidal cross section of the EXL-50 device. Nominal toroidal field is $1 \mathrm{~T}$ at $\mathrm{R}=0.24 \mathrm{~m}$. $\mathrm{b}$ Top view of EXL-50. The lines of sight of interferometer and HX diagnostics are indicated in the figure. The ECRH beam is aimed at the center of the machine when the toroidal injection angles is 00 . 


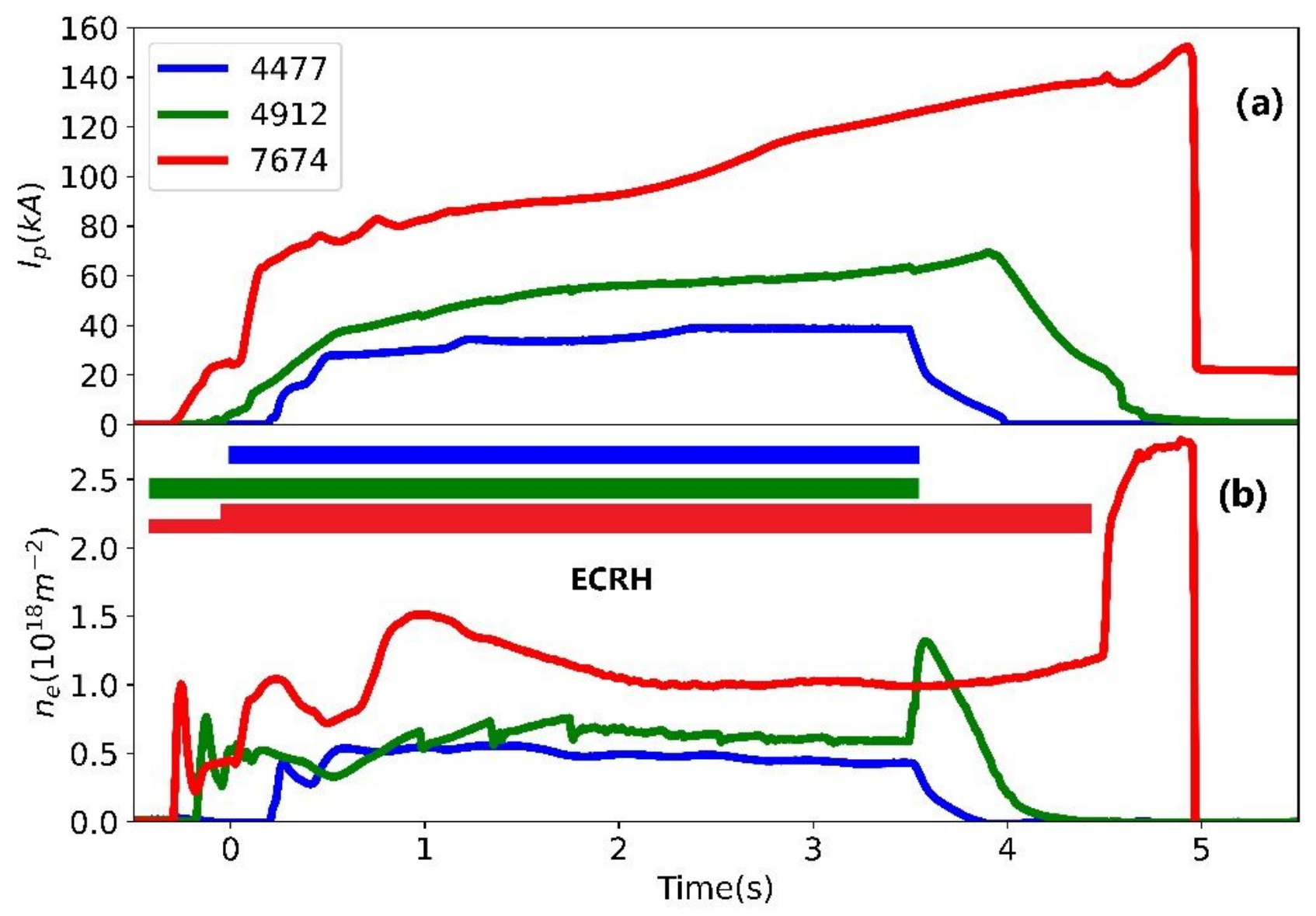

Figure 2

The discharge waveforms for different $28 \mathrm{GHz}$ ECRH heating power. (a) plasma current; (b) line integrated density. PECRH was $20 \mathrm{~kW}$ in shot 4477 and $45 \mathrm{~kW}$ in shot 4912 . Two gyrotrons are used in shot 7674 . One gyrotron injected $20 \mathrm{~kW}$ from $-0.3 \mathrm{~s}$ to $0 \mathrm{~s}$ and the other gyrotron injected $115 \mathrm{~kW}$ from $0 \mathrm{~s}$ to $4.5 \mathrm{~s}$. 


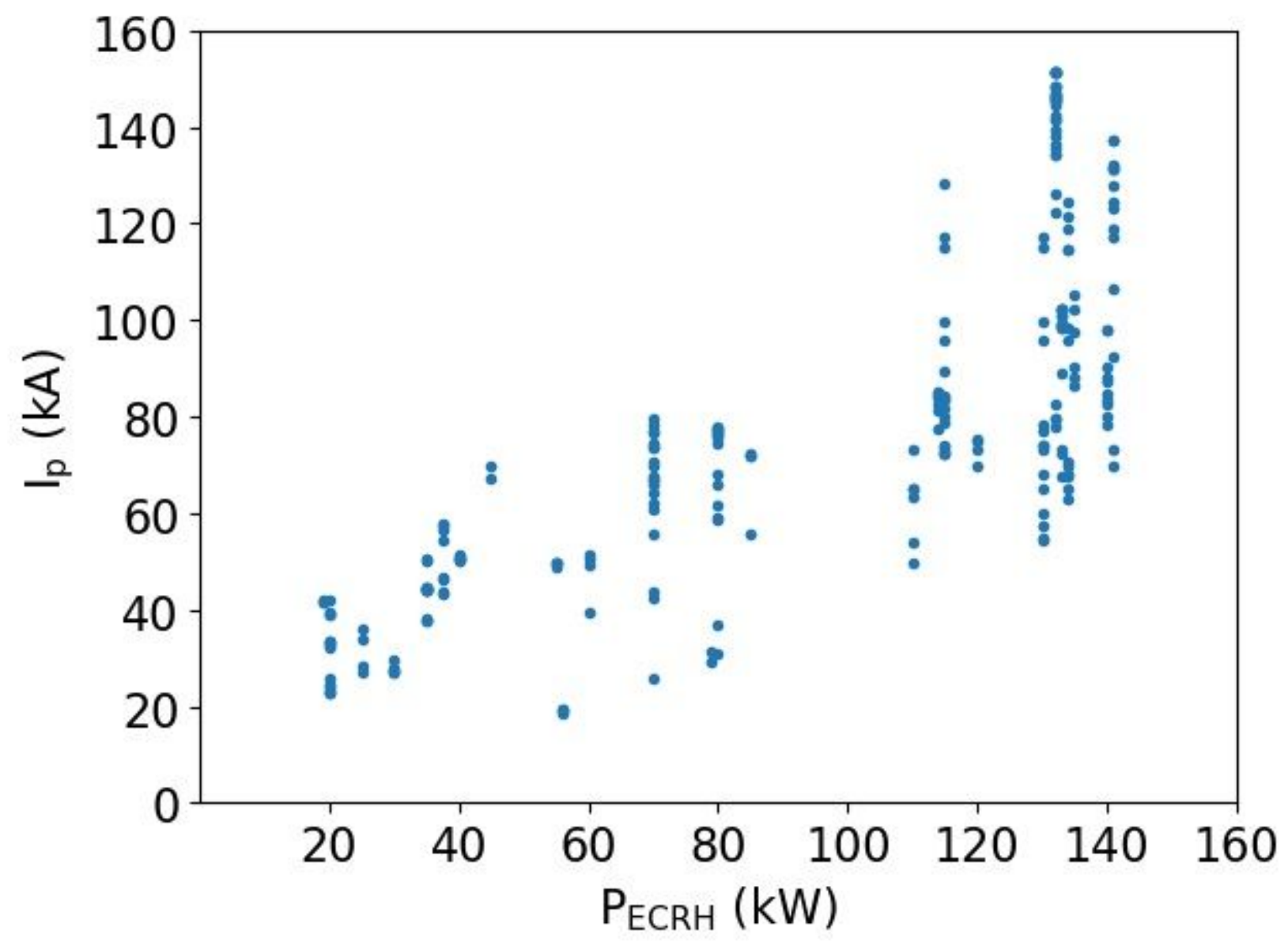

Figure 3

Ip v.s. PECRH for 180 successful shots in EXL-50

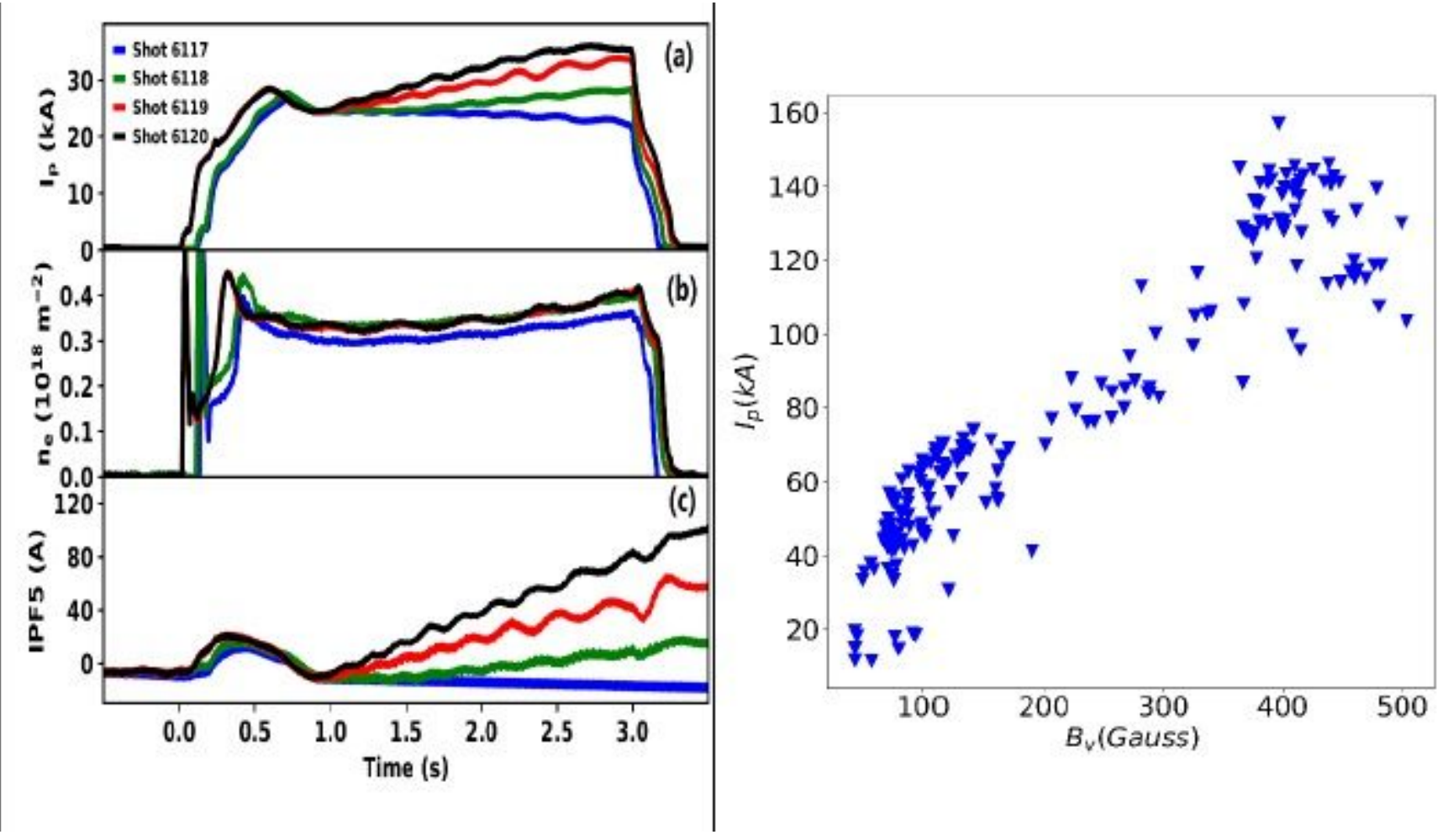


Figure 4

a The waveforms of four discharges with similar density. (a) plasma current; (b) line integrated density; (c) The electrical current of PF5. PECRH was $25 \mathrm{~kW}$ for these shots. The electrical current of PF1 and PF3 were kept constant during whole discharge phase. $\mathrm{b}$ The plasma current at flattop phase versus external Bv.

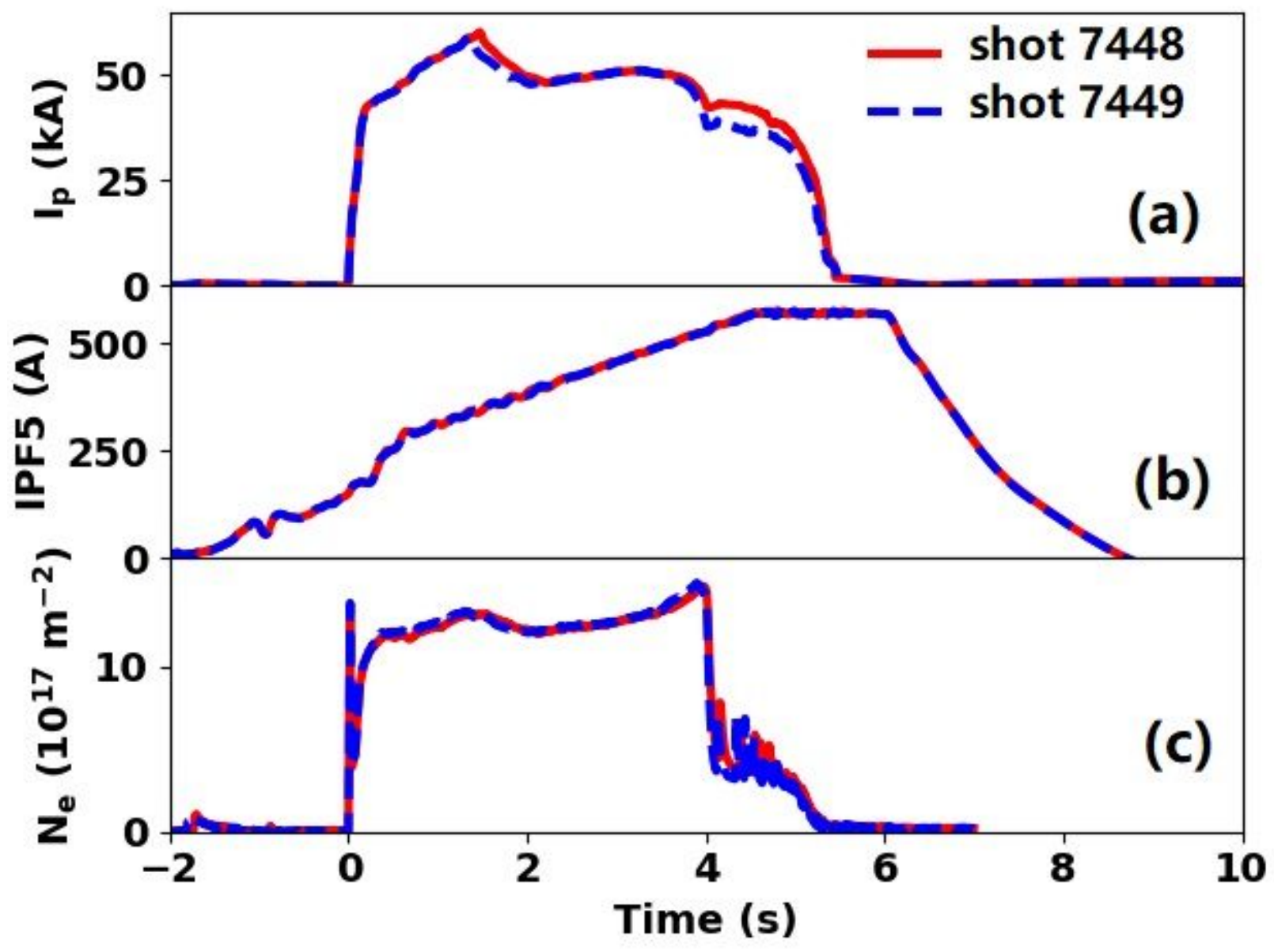

Figure 5

The waveforms of identical discharges with same density, ECRH power and PF current. (a) plasma current; (b) The electrical current of PF5; (b) line integrated density; 

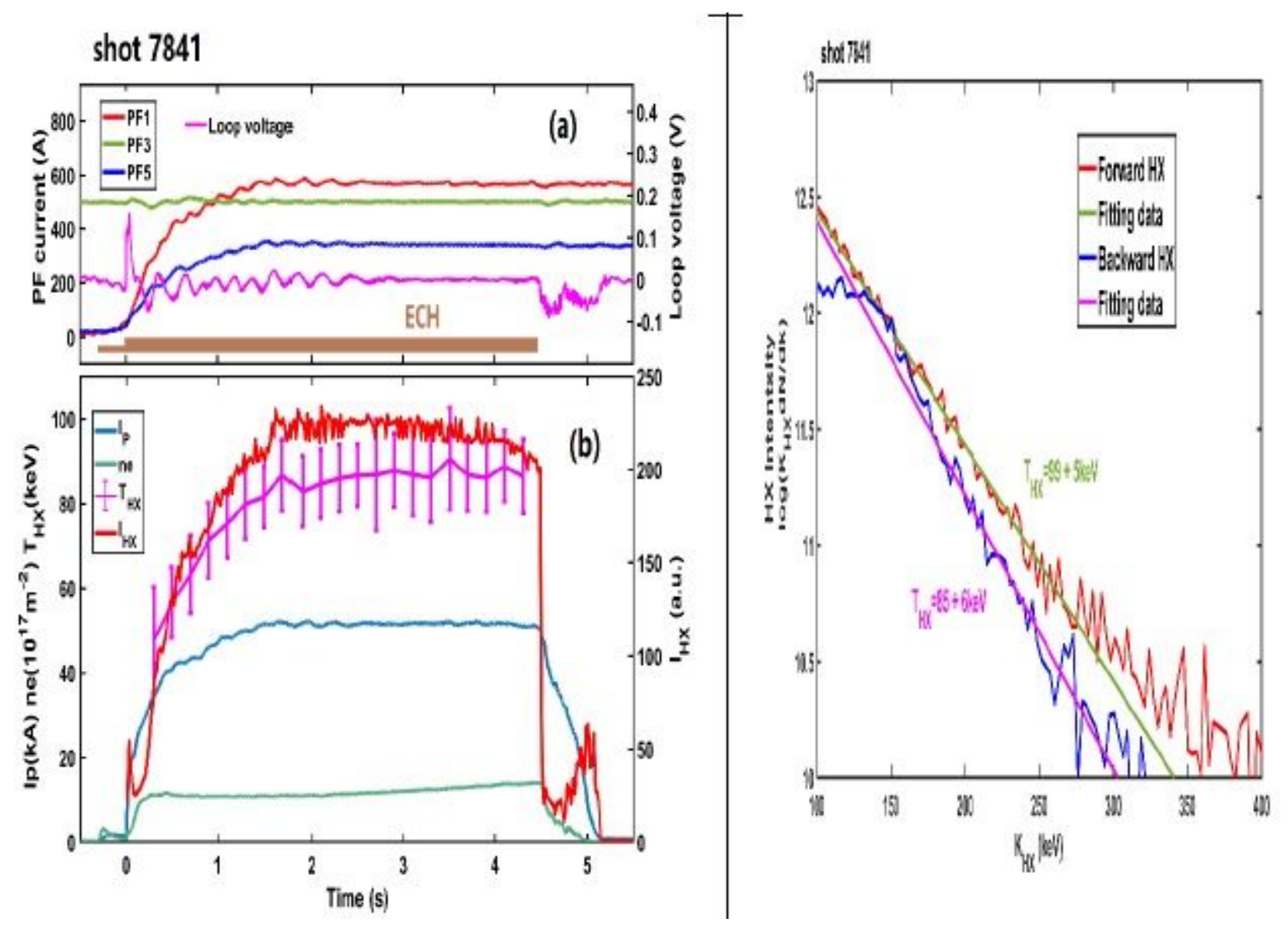

Figure 6

a (a) Waveforms of PF current (PF1, PF3, and PF5), loop voltage and ECRH. (b) waveforms of plasma current (Ip), density (ne), temperature (THX) and intensity (IHX) of hard x-ray. One gyrotron injected $10 \mathrm{~kW}$ from $-0.3 \mathrm{~s}$ to $0 \mathrm{~s}$ and the other gyrotron injected $100 \mathrm{~kW}$ from $0 \mathrm{~s}$ to $4.5 \mathrm{~s}$. $\mathrm{c} \mathrm{HX}$ spectrum (integrated time: $2 s \sim 2.2 s$ ) in forward and backward direction during flattop phase
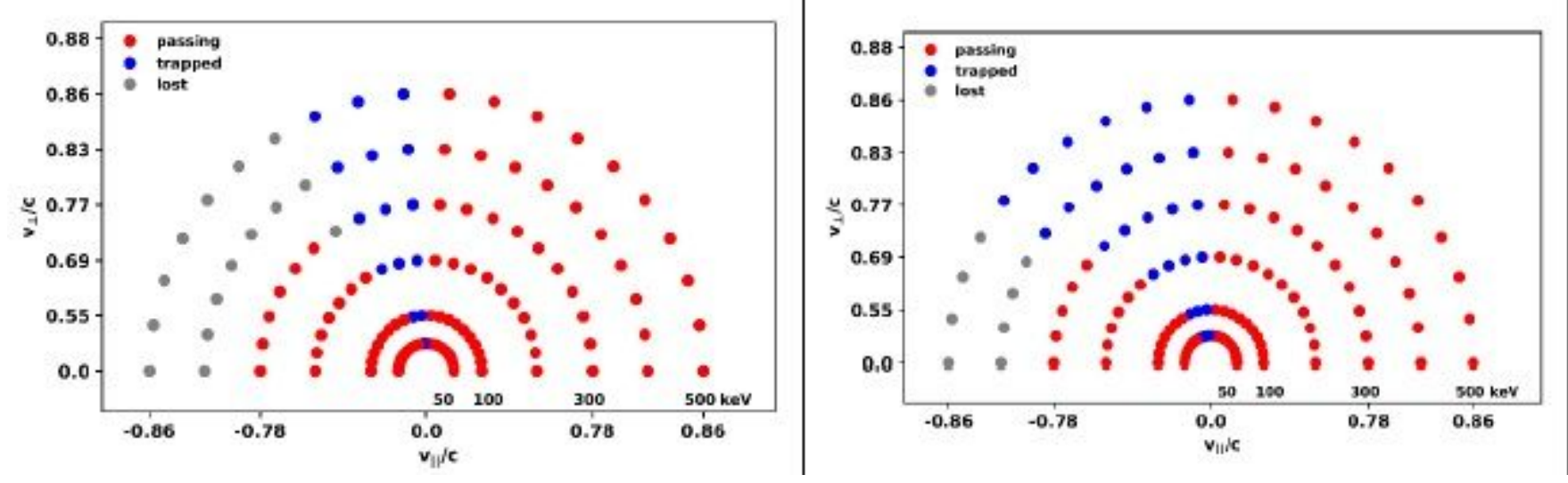

Figure 7

a Velocity distribution of energetic electrons which start from 1st harmonica layer at mid-plane. b Velocity distribution of energetic electrons which start from magnetic axis. 


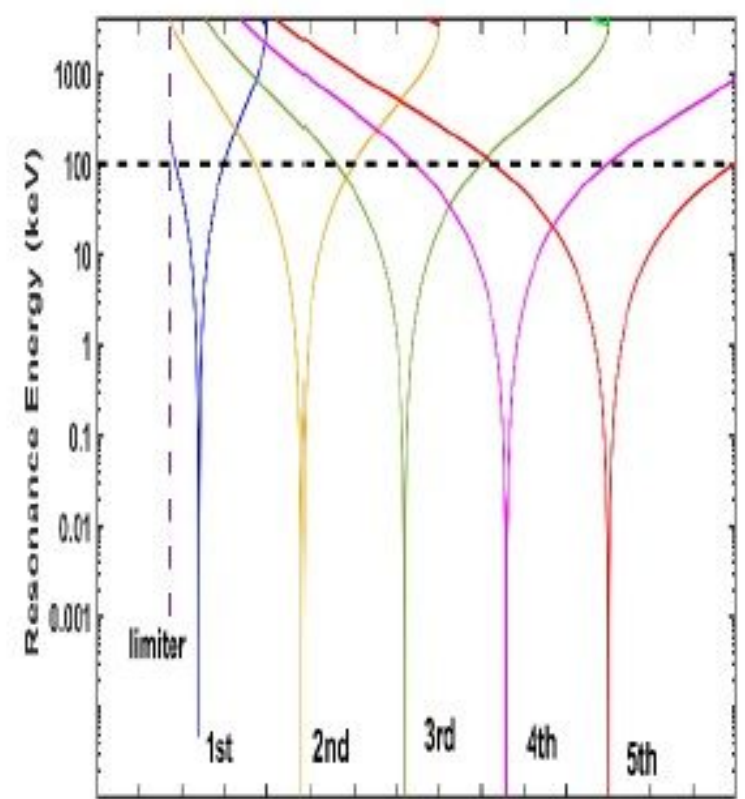

$\begin{array}{lllllllllllllllll}0 & 0.1 & 0.2 & 0.3 & 0.4 & 0.5 & 0.6 & 0.7 & 0.8 & 0.9 & 1 & 1.1 & 1.2 & 1.3 & 1.4 & 1.5\end{array}$ $R(m)$

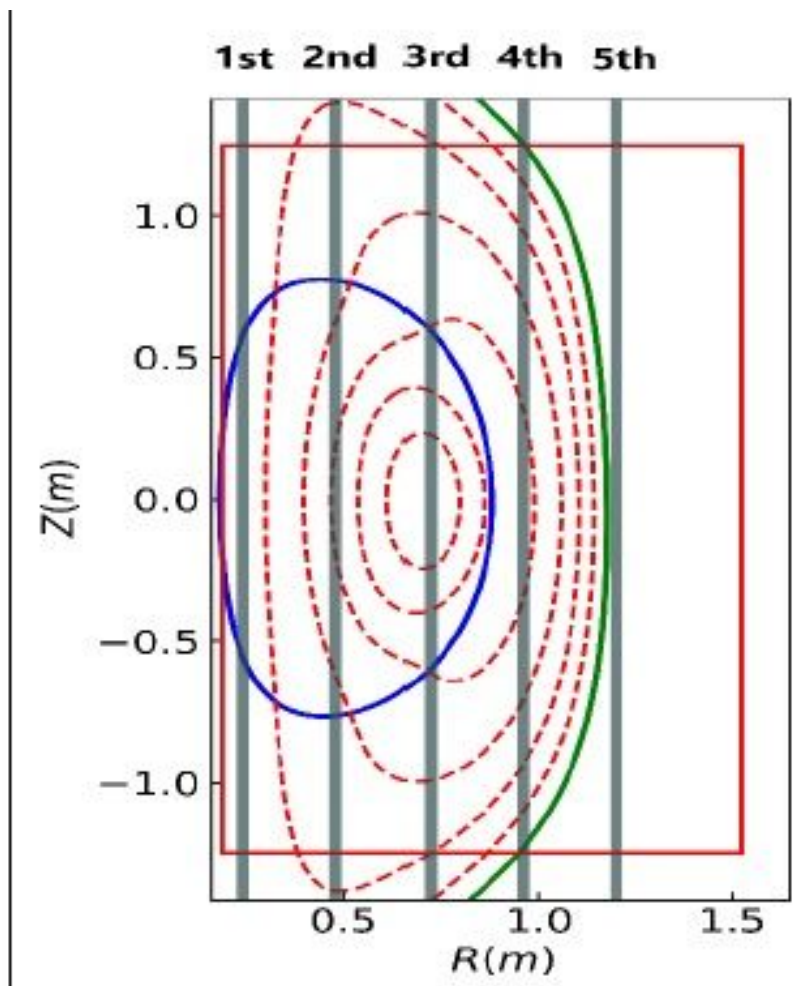

Figure 8

a Radial profiles of resonance energy for the harmonic ECW. b Reconstructed current density profiles by the multi-fluid equilibrium model. Blue line represents LCFS.
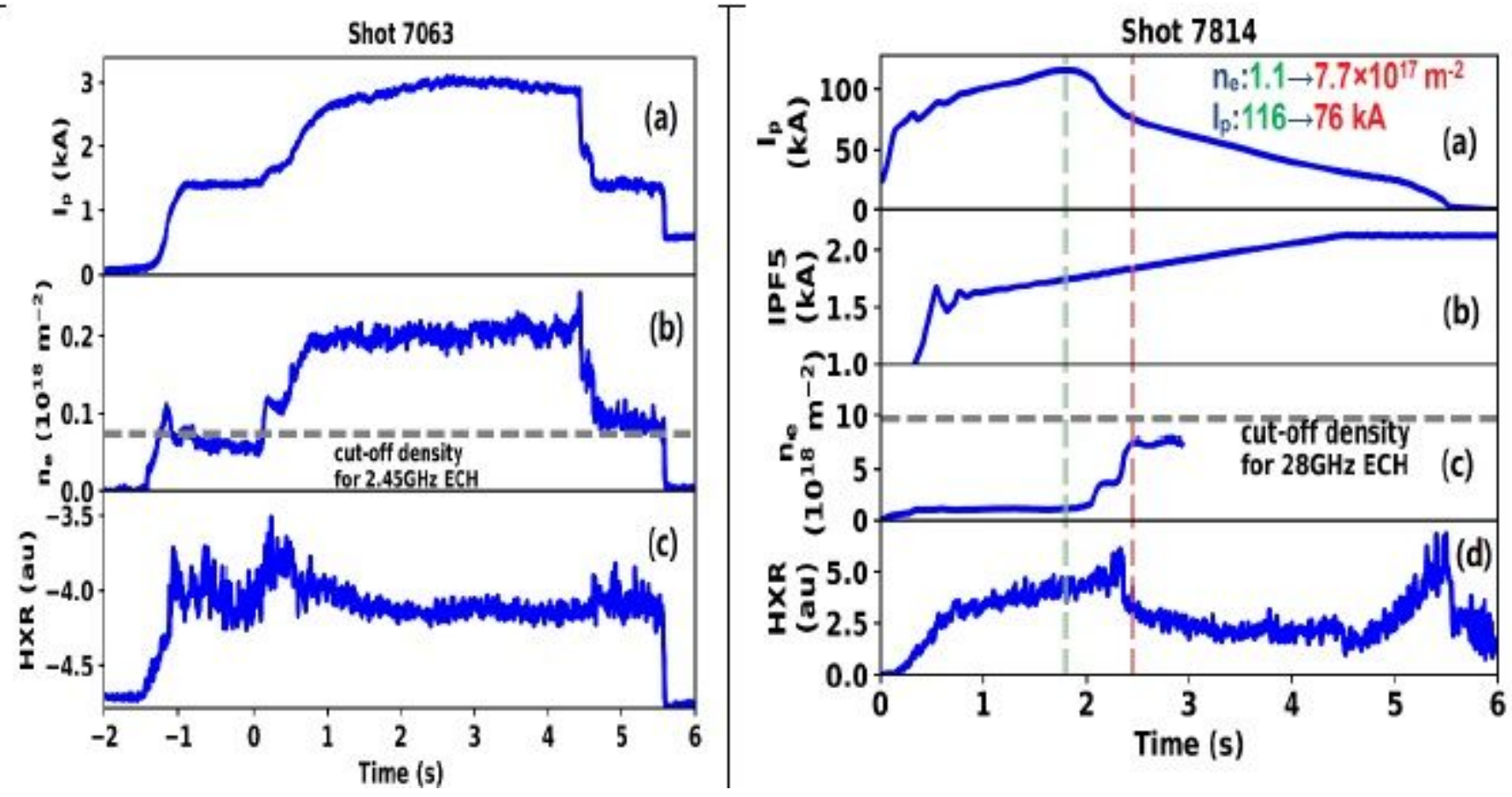

Figure 9

a Waveforms of high density discharge with $2.45 \mathrm{GHz}$ ECRH. PECRH was 20kW. (a) plasma current; (b) line integrated density; (c) intensity of hard x-ray. b Waveforms of high density discharge with $28 \mathrm{GHz}$ 
ECRH. PECRH was about $200 \mathrm{~kW}$. The density signal after $3 \mathrm{~s}$ is unavailable due to instrument failure. (a) plasma current; (b) electrical current of PF5; (c) line integrated density; (d) intensity of hard x-ray. 